\title{
Observation of Phase-Locked States in the Atlantic Multi-Decadal Oscillation (AMO)
}

\author{
David Holmes Douglass \\ Department of Physics and Astronomy, University of Rochester, Rochester, NY, USA \\ Email: douglass@pas.rochester.edu
}

How to cite this paper: Douglass, D.H. (2018) Observation of Phase-Locked States in the Atlantic Multi-Decadal Oscillation $(A M O)$. Atmospheric and Climate Sciences, 8, 344-354.

https://doi.org/10.4236/acs.2018.83023

Received: May 18, 2018

Accepted: July 23, 2018

Published: July 26, 2018

Copyright $\odot 2018$ by author and Scientific Research Publishing Inc. This work is licensed under the Creative Commons Attribution International License (CC BY 4.0).

http://creativecommons.org/licenses/by/4.0/

\begin{abstract}
We report that the Atlantic Multi-Decadal Oscillation ( $A M O)$ shows the same phase-locked states of period 2 and 3 years that have been reported in many other climate indices. In addition, we find that the report by Muller, Curry et al. of an oscillation in the $A M O$ of 9.1 years is a misinterpretation of a maximum in the Fourier spectrum.
\end{abstract}

\section{Keywords}

Climate Shift, El Niño, AMO, Phase-Locked States

\section{Introduction}

The $A M O$ index is the area weighted average sea surface temperature (SST) of the Atlantic Ocean from latitudes $0 \mathrm{~N}$ to $70 \mathrm{~N}$. The multi-decadal oscillation period is reported as $65-70$ years by Schlesinger et al. [1].

Studies of the $A M O$ on decadal time scales are few. Douglass [2] reported that the $A M O$ and three other climate indices all had the same climate shift dates and that these dates were the same as have been reported in other climate indices. Muller, Curry et al. [3] (henceforth MC2013) in a study of land surface temperature data also compared various $S S T$ data sets to the $A M O$ with a focus on the decadal range, which they characterize as 2 to 15 years.

In this paper we will point out that we already know that the $A M O$ has abrupt climate shifts [2] at certain dates and that inclusion of other indices shows that phase-locked states are observed between these dates. Thus, one would expect to find phase-locked states of $A M O$ between these dates. This paper will show that this expectation is borne out. For example, we find that between the $A M O$ shift dates 1986-87 and 2001-02 there is a phase-locked state of period 3 years. 


\section{Background Material}

We summarize results of prior investigations that will be discussed in this paper.

\subsection{Climate Shifts}

Abrupt shifts in various climate indices have been well documented. Trenberth [4] was among the first to report existence of an abrupt shift in a climate index in the Pacific Ocean during the mid-1970s.

Simultaneous climate shifts have been reported in a "global" set of indices [2]. The indices studied were:

- SST3.4, central tropical Pacific SST;

- $\quad N P C 1$ (PDO), Pacific Ocean between $20 \mathrm{~N}$ and $65 \mathrm{~N}$;

- $S P C 1$, southern Pacific SST; and

- $A M O$, the subject of this paper.

The climate shifts since 1950 are found to occur during the following years [2]:

- 1956-1959;

- 1964-66;

- 1969;

- 1976-77;

- 1986-87 and

- 2001-02.

Weaker shifts were found at other dates. This list is consistent with climate shifts reported in prior papers.

A question arises: From what to what does the climate shift refer? The answer is: from one phase-locked state to another phase- locked state. See next section.

\subsection{Phase-Locked States}

Phase-locked states in the Earth's atmosphere/ocean climate system have been reported by Douglass [5]. In this paper the El Niñol La Niña climate index SST3.4 was studied from 1870 to 2011. It was noticed in the record that certain time segments had sinusoid-like oscillations whose period appeared to be 2 or 3 years. A scheme novel to the application of climate indices was used to examine these time segments.

This scheme is called the autocorrelation method (AM) in which the autocorrelation of the time segment containing the 2- or 3-year oscillations was calculated $v s$. the delay time $\tau$. If this time segment contains a sinusoidal signal of period 2 or 3 years then the autocorrelation function will have a maximum at a delay of 24 or 36 months. See [5] for details. This scheme not only gave the periodicity, it also gave the beginning and the end dates. These dates corresponded closely to the dates of previous determined dates of climate shifts. The periodicity of 2 or 3 years was identified with the 2nd and 3rd subharmonic of an annual forcing. Ten phase-locked states were reported.

In a later paper Douglass [6] studied five Pacific climate indices that included 
SST3.4. The other four were:

- $S O I$, the Southern Oscillation Index;

- $M S U-l t$, equatorial lower troposphere temperature;

- $P D O$, the Pacific Decadal Oscillation ( $29 \mathrm{~N}$ to $65 \mathrm{~N})$; and

- $W 3$, an equatorial wind index.

All showed phase-locked states over nearly the same date ranges as SST3.4.

\subsection{Historic El Niño Episodes}

Douglass, Knox, Curtis, Giese and Ray [7] (henceforth DKCGR) studied the index SST3.4 in more detail. They defined and enumerated the historical El Niño episodes. This more complete study reported 18 phase-locked segments since 1872. Within each segment sinusoid-like oscillations were observed and characterized by the 3 discreet indices described in [2]. The positive maxima of these oscillations were identified with an El Niño episode. A total of 40 episodes were found and are listed in their Table 2.

\section{Data}

$A M O$

The $A M O$ index data are monthly values of the area weighted sea surface temperature (SST) of the Atlantic Ocean from the equator to $70 \mathrm{~N}$. The data range from 1856 to the present. We use the unsmoothed data set that can be downloaded at NOAA/AMO [8].

SST3.4

We also use the monthly values of El Nino/ La Nina index, SST3.4, for comparison. This data is the same that was used to defined and find 40 historical $E I$ Nino episodes. See [7].

The data in both sets are measured in degrees Centigrade.

\section{Analyzing $A M O$}

\subsection{Annual Term}

The first task is to remove the strong annual signal from the $A M O$. A very common method used to "remove" the annual signal is the "climatology" scheme. However, this scheme can lead to false signals in the derived anomaly index [9]. Also, in this paper a better scheme was proposed. In this better scheme the data was operated upon with a filter $f$ which is a running 12 -month average. This filter removes not only the 1.0-year signal exactly but also the harmonics. The data after application of $f$ on $A M O$ are labeled

$$
\text { AMO_12. }
$$

As in [5] we also define a "high" frequency index:

$$
h A M O=A M O-A M O_{-} 12
$$

Figure 1(a) shows a representative time segment of $h A M O$ from 1990 to 2000. One sees a 1 -year periodic signal of amplitude about $2^{\circ} \mathrm{C}$. The fact that the 


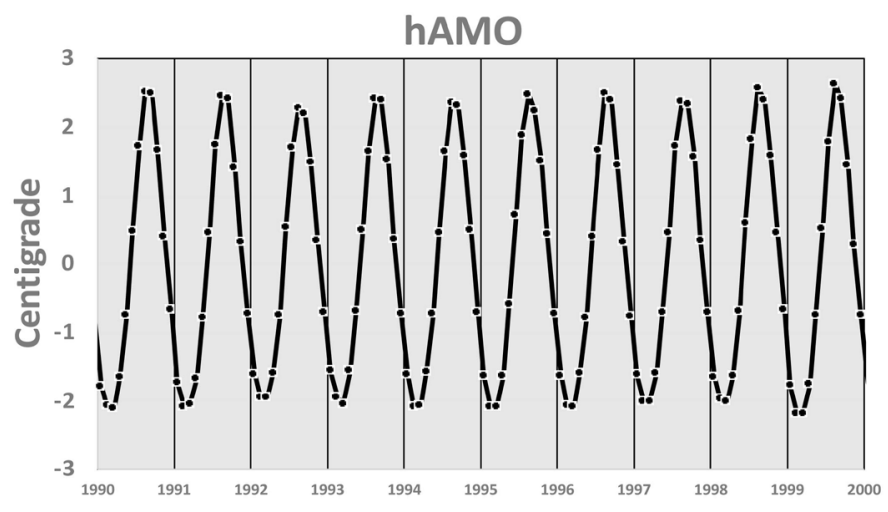

/Users/daviddouglass/Desktop/AMO figures/AMO unaltered_thru Aug 2017 Mar 23 2018.xlsx 4/2/18 1:04 PM

(a)

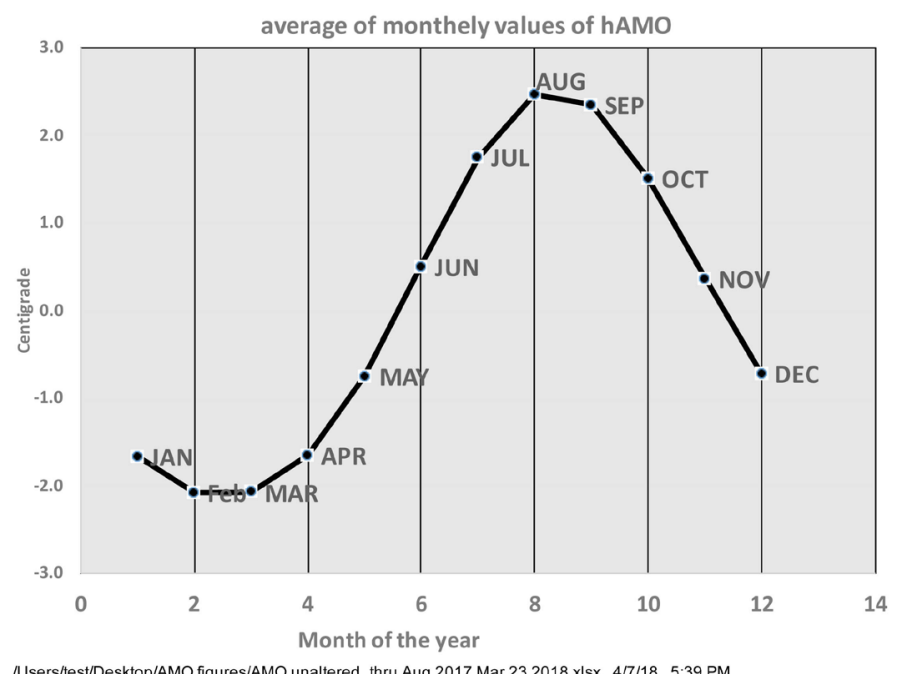

/Users/test/Desktop/AMO figures/AMO unaltered_thru Aug 2017 Mar 23 2018.xlsx 4/7/18 5:39 PM

(b)

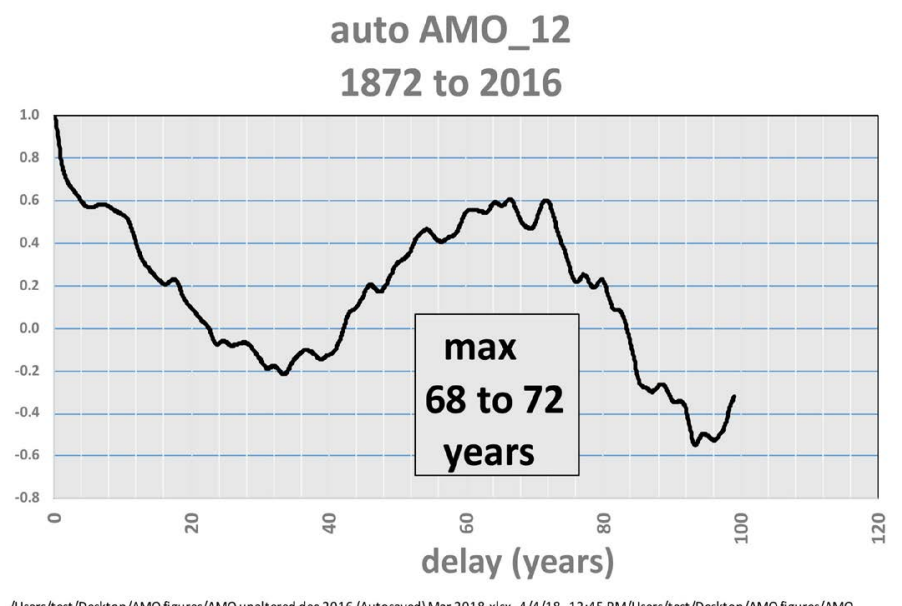

(c)

Figure 1. (a) Annual component $h A M O$ of the Atlantic Multi-decadal Oscillation, 1990-1999. See text for definition of $h A M O$; (b) Average of the monthly values of $h A M O$. The maximum occurs in August; (c) Autocorrelation of $A M O \_12$, which is the dataset $A M O$ with the annual component removed. The maximum at a delay of $68-72$ years gives a new estimate of the multi-decadal period. 
magnitude of the positive cycle is larger than the magnitude of the negative cycle means that there is a harmonic component.

Figure 1(b) shows the average of the monthly values of $h A M O$ over the same time interval. From this plot one sees that the maximum in $h A M O$ occurs between August and September.

Figure 1(c) shows the autocorrelation of $A M O-12$. The maximum at a delay of 68/72 years gives a new estimate of the multi-decadal period.

\subsection{Multi-Centennial Trend}

After the annual signal has been removed one sees that there is a multi-centennial trend that must be removed before an anomaly index can be defined. At this point in the analysis of $A M O \_12$ many investigators consider the global warming hypotheses as part of the trend and propose ways to model it. Some use a linear trend which is seen not to describe the trend. There is, in fact, no need to explain the trend. Just remove it imperially. Along with $a A M O \_12$ (red) in Figure 2(a) a second order polynomial fit is shown (black).

We define the $A M O$ anomaly as

$$
a A M O=A M O \_12-\text { polynomial }
$$

\subsection{The Multi-Decadal Oscillation Period}

Figure 2(b) shows aAMO (in red). The multi-decadal oscillation is shown by a running average over 120 months and is labeled aAMO_120. This curve is sinusoid-like. The positive values of aAMO_120 are usually called "warm" time intervals (Figure 2(b), black) which are

- 1863 to 1901 ;

- 1927 to 1965 ;

- 1997 to ? (see discussion below on this value).

These values are listed in Table 1 along with the values from Klotzbach et al. [10].

What is the value of the multi-decadal period?

Figure 2(c) shows the autocorrelation of $a A M O \_12$ vs. delay time. The delay time at the maximum is the oscillation period which is estimated as 68 to 72

Table 1. Warm time intervals of $A M O$.

\begin{tabular}{cccc}
\hline \multicolumn{2}{c}{ WRM Time Intervals } & \\
\hline & & begin & end \\
\hline 1 & This paper & 1863 & 1901 \\
& Klotzbach et al. $[10]$ & 1878 & 1899 \\
2 & This paper & 1927 & 1965 \\
& Klottzbach & 1959 \\
& This paper & 1926 & $2030-2035$ \\
& Klotznach & 1997 & 2012 \\
\hline
\end{tabular}




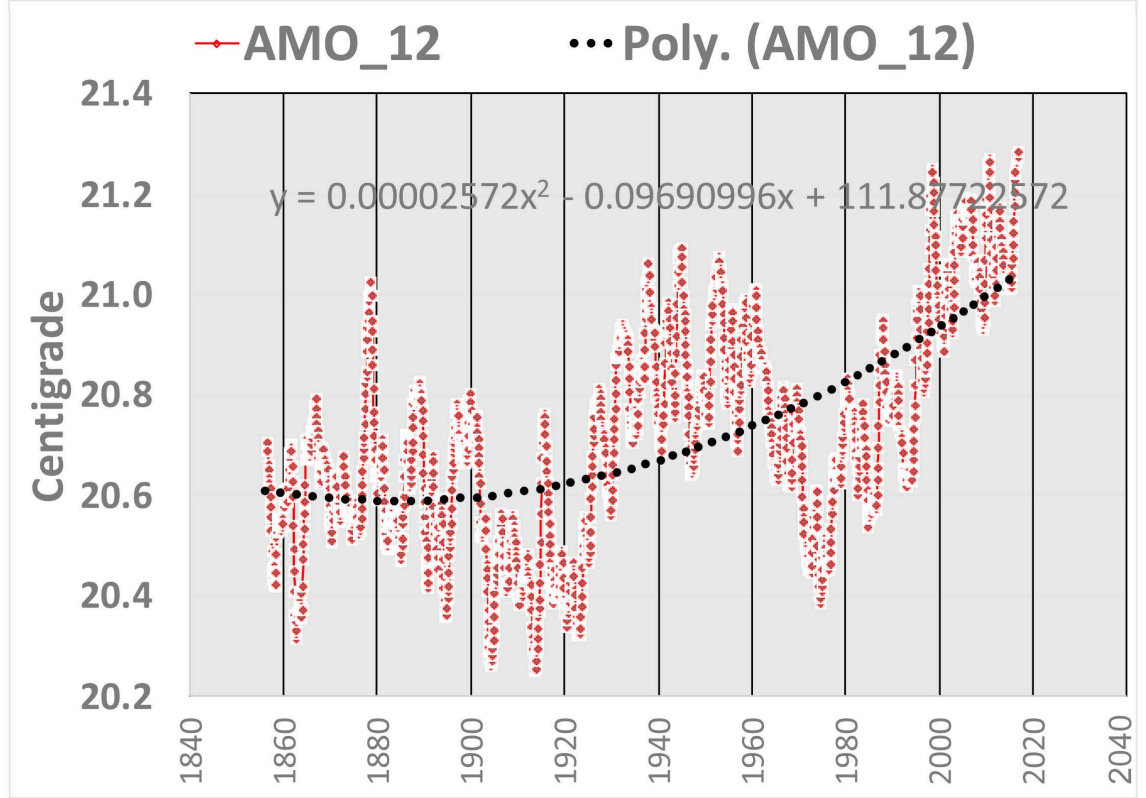

/Users/test/Desktop/AMO figures/AMO unaltered_thru Aug 2017 Mar 23 2018.xlsx 4:39 PM 4/4/18/Users/test/Desktop/AMO figures/AMO unaltered_thru Aug 2017 Mar 23 2018.xIsx 4/4/18 4:39 PM

(a)

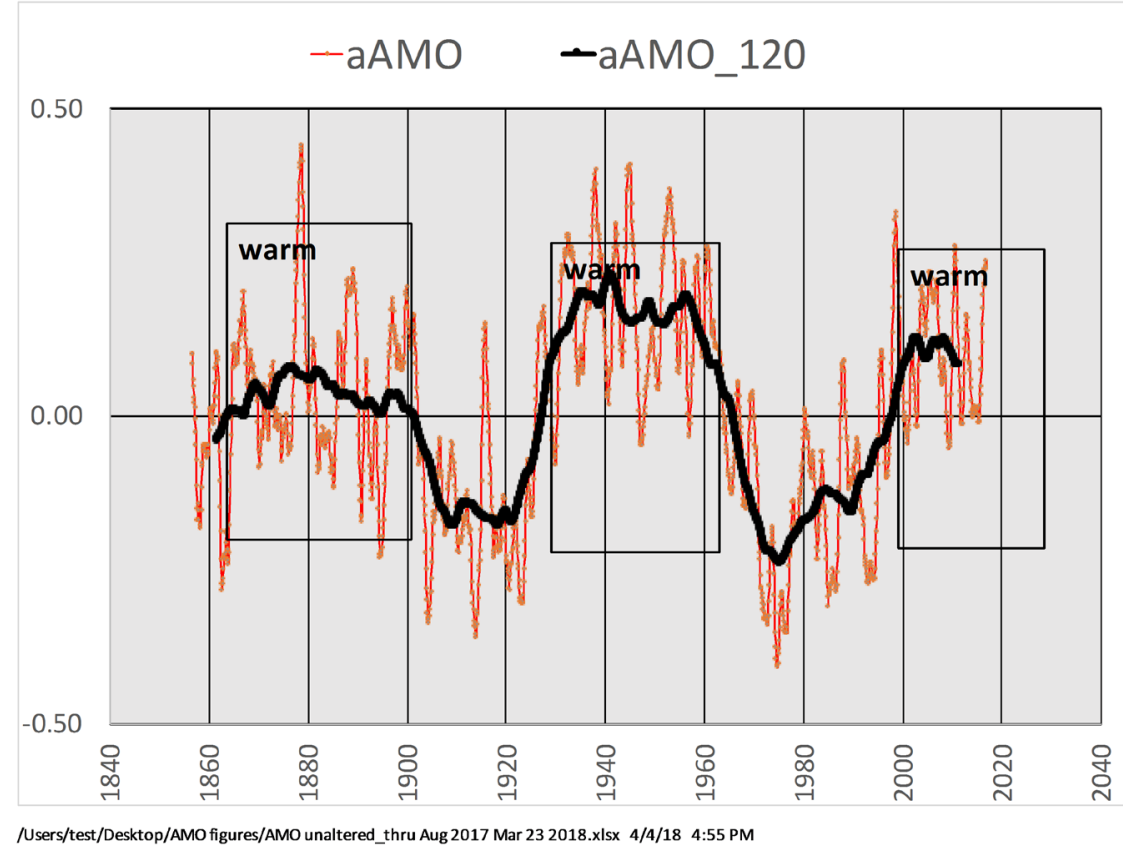

(b)

Figure 2. (a) $A M O \_12$ and a polynomial fit, $20.6057-0.00130 x+0.0000263 x^{2}$, where $x$ is the number of years past 1860. (b) $a A M O$ (red) and 120 -month-filtered version $a A$ $M O \_12$ (black). "Warm" time intervals are indicated by tinted rectangles.

years. This new estimate is close to the value of $65-70$ years given by [11]. The structure seen on this plot is due to the decadal effects that are considered in the next section.

When does the third warm time interval end? 
Using the 68 - 72-year value for the period then adding it to the end of warm segment 2, the estimate for the end of segment 3 is 2030 - 2034.

Some have suggested that the third warm time segment has already ended [10]. Our analysis indicates that it has not.

\section{Phase-Locked States in AMO_12}

Here we do not need to use anomalies to determine phase-locked states. We compare AMO_12 to the previously published results on SST3.4 [7], which showed phase-locked states. We have studied $A M O \_12$ from the mid-19th century and have observed the phase-locked phenomena. However, only results from data since 1990 are shown.

Figure 3 shows the SST3.4_12 data (black) and the date range of each SST3.4_12 phase-locked state is indicated by a tinted rectangle. Figures 3(a)-(c) shows phase-locked states 9, 10 and 11 of SST3.4_12. In addition, the various EI Niño episodes listed in DKCGR are indicated by their assigned number.

\subsection{Phase-Locked Segments of AMO_12}

Figure 3(a) shows both $A M O \_12$ (red) and SST3.4_12 (black) from 1991 to 2002. This time interval contains phase-locked segment 9 of SST3.4_12 with a period of 3 years, which was determined by the AM method. The range was from about June 1992 to about January 1999. The three maxima are the three El Niño episodes contained in this phase-locked state. These are labeled 32, 33 and 34 by DKCGR. Episode 34 is better known as “the El Niño of 1997/1998”. We now examine $A M O \_12$. One sees that this plot also shows a signal with 3 maxima spaced about 3 years apart. These maxima occur after the maxima in SST3.4_12. The delays are 17, 11 and 11 months, respectively.

The $A M O \_12$ data were also analyzed by the autocorrelation method. When the beginning date was about April 1992 and the ending date was about April 2002 the plot in Figure 4 was obtained. The maximum of the autocorrelation function occurs at a delay of 36 months. Thus, this time segment has an oscillation with a period of 3 years.

Figure 3(b) shows $A M O \_12$ and SST3.4_12 from 1999 to 2008. This time segment includes phase-locked segment 9 of SST3.4_12 of period 2 years. There are 3 El Nino episodes labeled 35, 36 and 37 spaced 2 years apart. The date range of this SST3.4_12 phase-locked state is from about January 2001 to about March 2009. One sees that there are also 3 maxima in $A M O \_12$ that occur after the maxima in SST3.4_12. The corresponding lags are 9, 12 and 14 months, respectively.

Figure 3(c) shows the time interval containing phase-locked segment 11 of SST3.4_12. This segment began at about March 2009 and is ongoing [11]. The signature of this aSST3.4_12 phase-locked state is the three maxima spaced 3 years apart. The 3 maxima are El Niño episodes 38, 39 and 40. Douglass has predicted that a fourth maximum may occur during the boreal winter of 2018 [11]. 


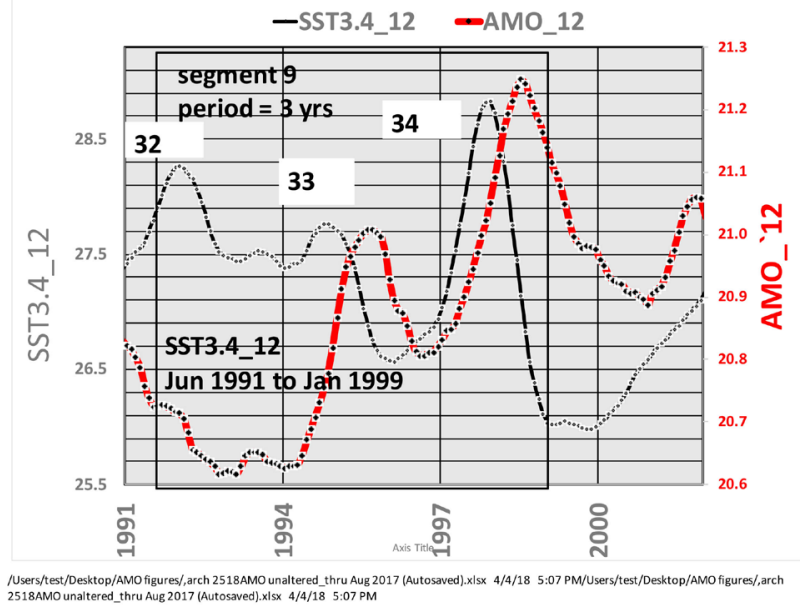

(a)

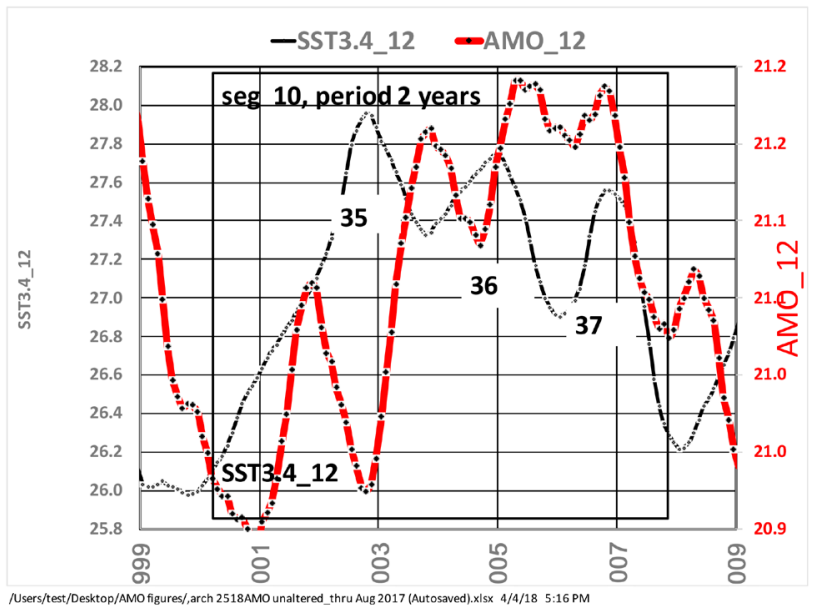

(b)

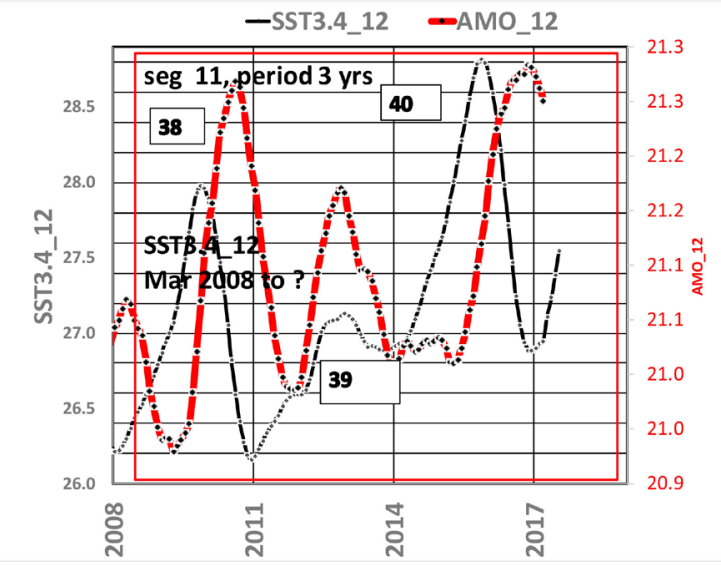

(c)

Figure 3. (a) SST3.4_12 (black), left scale, and $A M O \_12$ (red). The phase-locked segment 9 of period three years is indicated by a tinted rectangle. The three numbered maxima of SST3.4 are the three El Niño episodes as identified in reference 7; (b) Same as (a) except for phase-locked segment 10 of period two years; (c) Same as (a) except for phase-locked segment 11 of period three years. 


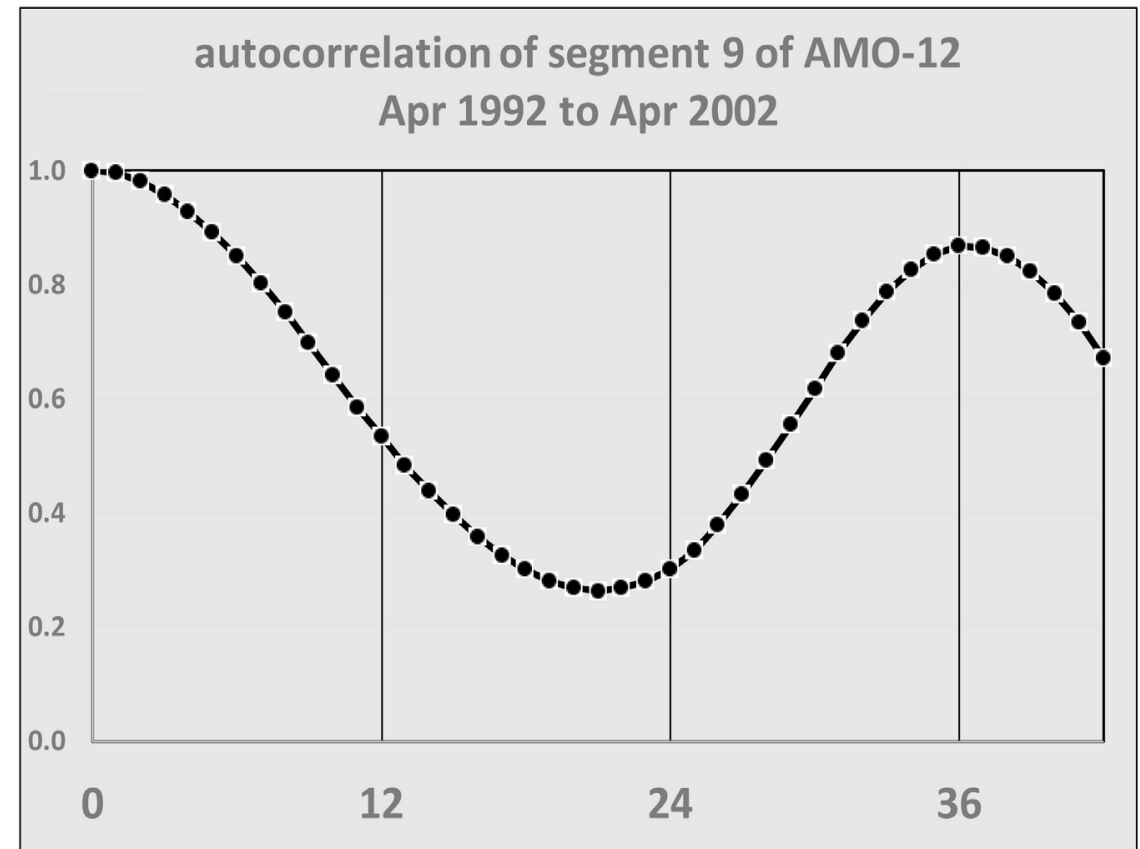

/Users/test/Desktop/AMO figures/AMO unaltered dec 2016 (Autosaved) Mar 2018.xlsx 4/9/18 11:15 AM/Users/test/Desktop/AMO figures/AMO unaltered dec 2016 (Autosaved) Mar 2018.xlsx 11:15 AM

Figure 4. Autocorrelation of AMO_12 from April 1992 to April 2002. The maximum at 36 months verifies that $A M O \_12$ has a period of three years during this time.

One sees that there are 3 maxima in $A M O_{-} 12$ that occur after the 3 maxima of SST3.4_12. The lags are: 7, 0 and 12 months, respectively.

\subsection{AMO_12 Lags SST3.4_12}

From Figures 3(a)-(c) one sees that each maximum in $S S T_{-} 12$ is followed by a maximum in $A M O \_12$. Table 2 lists the dates of these maxima and their differences. The average and standard deviation of the delays are $11 \pm 5$ months.

We also calculated a delayed correlation plot of aAMO_12 vs. aSST3.4_12 from 1950 to 2016 (not shown). We found a maximum in the correlation coefficient of 0.77 when the $a A M O \_12$ delay was 11 months. The associated relationship can be quantified as follows:

$$
\text { aAMO_12 }=0.1103 * \text { aSST3.4_12+0.11. }
$$

One sees that decadal changes in $A A M O \_12$ are about 10 times smaller than changes in aSST3.4_12. Thus, these two methods of estimating delay are consistent with each other.

\section{Discussion}

Muller, Curry et al. [3] (MC2013) studied the correlation of land temperatures vs. various other surface temperature climate indices since 1950 also studied other indices. Two of them, AMO and SST3.4, are the same as studied in more detail here. Their findings that concern us are as follows:

1) A high correlation of $S S T 3.4$ and AMO with $A M O$ lagging by a few months. 
Table 2. Time Delay of $A M O \_12$ after SST3.4_12.

\begin{tabular}{|c|c|c|c|c|c|c|}
\hline & & SST3.4_12 & & & $A M O \_12$ & \\
\hline Seg & Range & $\begin{array}{c}\text { State }^{*} \\
\text { n parity s }\end{array}$ & $\begin{array}{l}\text { El ñino } \\
\text { episode }\end{array}$ & $\begin{array}{c}\text { Date of } \\
\max \end{array}$ & Date of max & $\begin{array}{l}\text { Difference } \\
\text { (months) }\end{array}$ \\
\hline \multirow{3}{*}{9} & \multirow{3}{*}{$\begin{array}{c}\text { Jun } 91 \text { to } \\
\text { Jan } 99\end{array}$} & \multirow{3}{*}{3 ortho 0} & 32 & Jan 82 & Jul 93 & 17 \\
\hline & & & 33 & Oct 94 & Jul 95 & 11 \\
\hline & & & 34 & Nov 07 & Aug 98 & 11 \\
\hline \multirow{3}{*}{10} & \multirow{3}{*}{$\begin{array}{l}\text { Jan } 01 \text { to } \\
\text { Mar } 08\end{array}$} & \multirow{3}{*}{2 ortho 0} & 35 & Dec 02 & Sep 03 & 9 \\
\hline & & & 36 & Jan 05 & Jul 05-Jul 06 & 12 \\
\hline & & & 37 & Nov 06 & Jun 08 & 14 \\
\hline \multirow{4}{*}{11} & \multirow{4}{*}{$\begin{array}{c}\text { Mar } 09 \\
\text { to ? }\end{array}$} & \multirow{4}{*}{3 ortho 0} & 38 & Dec 09 & Jul 10 & 7 \\
\hline & & & 39 & Nov 12 & Nov 12 & 0 \\
\hline & & & 40 & Nov 15 & Nov 16 & 12 \\
\hline & & & 41 & Nov 18 & & \\
\hline
\end{tabular}

2) A claim of a strong signal in $A M O$ of a period of $9.1 \pm 0.4$ years.

MC2013 show a plot of spectral power $v s$. the frequency in cycles/year for $A M O$. This plot has a narrow maximum at about 0.11 cycles/year ( 9.1 years) and a second and third maxima but are slightly smaller maximum at about 0.28 and 0.34 cycles/year (3.5 and 2.9 years), which we will label maxima 1, 2 and 3 . We will call this combination of three maxima the "signature".

\section{Comments on MC2013}

1) Our result of $A M O$ lagging $S S T 3.4$ by $11 \pm 5$ months is consistent with the findings of MC2013.

2) Since our more detailed study of $A M O$ found no signal of period 9.1 years we did a Fourier analysis of $A M O$. We calculated the Fourier spectrum of $A M O$ using a fast Fourier transform (FFT) and obtained a plot with the same signature as reported by MC2013 and with the same 3 maxima. Thus, we agree. What is the explanation? While it is true that a periodic signal will result in a maximum in the Fourier spectrum the converse may not be true. In this case there is no 9.1 year periodic signal in $A M O$ corresponding to the maximum in the Fourier spectrum. Also, if there were a signal of 9.1 years in ZMO there would be a maximum in the delayed autocorrecting function at a delay of 9.1 years. We calculated the autocorrelation function of $A M O$ from 1950 to 2017 (the same range as in MC2013). We obtained a plot (not shown) almost the same as in Figure 1(c) with no maximum at a delay of 9.1 years.

We conclude that the claim of MC2013 of a 9.1 year periodic signal is an error in interpretation of a maximum in the Fourier spectrum of $A M O$.

\section{Conclusions}

We have measured the $A M O$ multi-decadal period to be $68-72$ years which is 
close to the value of 65 to 70 years found in the literature. We also estimate that the present "warm" time interval will not end until about 2031/2035.

More importantly, we find that the $A M O$ has time segments showing the same phase-locked states of periods 2 and 3 years as reported in many other climate indices. However, the AMOlags the SST3.4 by about a year.

In addition, we conclude that interpreting a maximum in the Fourier spectrum of $A M O$ as an oscillation in $A M O$ of period of 9.1 years is incorrect.

\section{Acknowledgements}

We wish to acknowledge helpful comments from P Klotzbach and R.S. Knox.

\section{References}

[1] Schlesinger, M. and Ranankutty, N. (1994) An Oscillation in the Global Climate System of Period 65-70 Years. Nature, 367, 723-726. https://doi.org/10.1038/367723a0

[2] Douglass, D.H. (2010) Topology of Earth's Climate Indices and Phase-Locked States. Physics Letters A, 374, 4164-4168.

[3] Muller, A.R., Curry, J., Groom, D., Jacobson, R., Perlmutter, S., Ronde, R., Rosenfeld, A., Wickhamand, C. and Wurtle, J. (2013) Decadal Variation in the Global Atmospheric Land Temperatures. Journal of Geophysical Research: Atmospheres, 118, 5280-5286. https://doi.org/10.1002/jgrd.50458

[4] Trenberth, K.E. (1990) Recent Observed Interdecadal Climate Changes in the Northern Hemisphere. Bulletin of the American Meteorological Society, 71, 988-993. https://doi.org/10.1175/1520-0477(1990)071<0988:ROICCI>2.0.CO;2

[5] Douglass, D.H. (2011) The Pacific Sea Surface Temperature. Physics Letters A, 376.

[6] Douglass, D. (2013) Phase-Locked States and Abrupt Shifts in Pacific Climate Indices. Physics Letters A, 377, 1749-1755.

[7] Douglass, D.H., Knox, R.S., Curtis, S., Giese, B.S. and Ray, S. (2017) Historical Phase-Locked El Niño Episodes. Atmospheric and Climate Sciences, 7, 48-64. https://doi.org/10.4236/acs.2017.71005

[8] NOAA/CPC (2017) SST3.4 and Niño3.4. http://www.cpc.ncep.noaa.gov/data/indices/

[9] Douglass, D.H. (2011) Separation of a Signal of Interest from the Seasonal Effect in Geophysical Data: I. El Niño/La Niña Phenomenon. International Journal of Geosciences, 2, 414-419. https://doi.org/10.4236/ijg.2011.24045

[10] Klotzbach P., Gray, W. and Fogarty, C. (2015) Active Atlantic Hurricane Era at Its End? Nature Geoscience, 8, 737-738. https://doi.org/10.1038/ngeo2529

[11] Douglass, D. (2018) An El Nino That Failed to "Appear", an El Nino That Was "Hiding" and a Prediction of the Next El Ñino. Atmospheric and Climate Science, 8, 55-82. https://doi.org/10.4236/acs.2018.81004 